\title{
Homogeneously Catalyzed Transesterification of Nigerian Jatropha curcas Oil into Biodiesel: A Kinetic Study
}

\author{
Elizabeth Funmilayo Aransiola ${ }^{1,2 *}$, Michael Olawale Daramola ${ }^{3}$, Tunde Victor Ojumu², \\ Bamidele Ogbe Solomon ${ }^{1}$, Stephen Kolawole Layokun ${ }^{1}$ \\ ${ }^{1}$ Biochemical and Reaction Engineering, Department of Chemical Engineering, Obafemi Awolowo University, Ile-Ife, Nigeria \\ ${ }^{2}$ Department of Chemical Engineering, Cape Peninsula University of Technology, Cape Town, South Africa \\ ${ }^{3}$ School of Chemical \& Metallurgical Engineering, Faculty of Engineering \& The Built Environment, \\ University of the Witwatersrand, Johannesburg, South Africa \\ Email: *aransiola4@yahoo.com
}

Received January 1, 2013; revised February 8, 2013; accepted March 5, 2013

Copyright (C) 2013 Elizabeth Funmilayo Aransiola et al. This is an open access article distributed under the Creative Commons Attribution License, which permits unrestricted use, distribution, and reproduction in any medium, provided the original work is properly cited.

\begin{abstract}
As a follow-up to our previous study on the transesterification of Nigerian Jatropha curcas oil into Biodiesel using homogenous catalysis, kinetic study of the reaction is hereby presented. The kinetic study revealed that the rate of formation of biodiesel can be increased by increasing reaction temperature and oil to alcohol molar ratio. The optimum reaction condition was established to be $60^{\circ} \mathrm{C}$ (reaction temperature) and 1:6 (oil to alcohol ratio). Accordingly, the highest biodiesel yield obtained from homogeneously catalyzed transesterification of Nigerian Jatropha curcas (JC) oil into Biodiesel was $86.61 \% \mathrm{w} / \mathrm{w}$ at $60^{\circ} \mathrm{C}$ with oil to alcohol ratio of $1: 6$. Furthermore, kinetic study also revealed that conversion of triglyceride to diglyceride was the rate determining step (RDS) of the overall reaction because activation energy of its backward reaction is lower than that of the forward reaction, indicating unstable nature and higher potential energy of the diglyceride in comparison to the triglyceride.
\end{abstract}

Keywords: Homogenous Catalysis; Transesterification; Biodiesel; Jatropha curcas

\section{Introduction}

The world's quest for alternative fuel due to fear of depletion of petroleum reserves and environmental benignity have led to the production of biodiesel [1-3]. Therefore production of biodiesel (BD) is becoming very important since the feedstock for producing $\mathrm{BD}$ is obtained from renewable source like vegetable oils. However, the use of these oils competes with food production and consumption, so recent researches efforts have been channeled towards the use of waste vegetable oils and nonedible oils for BD production [4-8].

Biodiesels are monoalkyl esters of long chain fatty acids derived via transesterification of large, branched triglycerides (TG), using an homogeneous alkali or acid as catalyst. The main mechanism of this reaction involves the three stepwise reactions. The triglyceride is converted stepwise to diglyceride (DG), monoglyceride (MG) and finally glycerol (GL) as shown below [9] and a mole of ester is liberated at each step.

*Corresponding author.
Overall reaction

$$
T G+3 R^{\prime} \mathrm{OH} \leftrightarrow 3 R^{\prime} \mathrm{COOR}+G L
$$

$\underline{\text { Stepwise reactions }}$

$$
\begin{array}{cc}
k_{1} \\
T G+R^{\prime} \mathrm{OH} \leftrightarrow D G+R^{\prime} \mathrm{COOR} \\
k_{11} \\
k_{2} \\
D G+R^{\prime} \mathrm{OH} \leftrightarrow M G+R^{\prime} \mathrm{COOR} \\
k_{22} \\
k_{3} \\
M G+R^{\prime} \mathrm{OH} \leftrightarrow G L+R^{\prime} \mathrm{COOR} \\
k_{33}
\end{array}
$$

Freedman investigated transesterification of soybean oil using butanol and methanol, with molar ratios of alcohol to oil of $30: 1$ and 6:1, at temperatures ranging from $20^{\circ} \mathrm{C}$ to $60^{\circ} \mathrm{C}$. With butanol, the author concluded that the forward reactions obey second order reaction at $6: 1$ 
and pseudo-first order at 30:1. Also with methanol, the forward reactions were of a fourth order at 6:1, implying the shunt reaction, and pseudo-first order at 30:1. In all cases, all the reverse reactions were found to be second order.

Reaction rate constant as a function of temperature is given by Arrhenius depicted in Equation (5) and linearization of Equation (6) yields:

$$
\begin{aligned}
& k=A \exp \left(\frac{-E_{a}}{R T}\right) \\
& \ln (k)=-\frac{E_{a}}{R T}+\ln (A)
\end{aligned}
$$

where $A$ is the Arrhenius pre-factor and $E_{a}$ is the activation energy of the reaction. This equation is linear with respect to $1 / \mathrm{T}$. If $k$ is determined for varying temperatures, the plot of $\ln (k)$ vs. 1/T should produce a straight line of slope $-E_{a} / R$.

According to a study from Noureddini and Zhu [10] on transesterification of soybean oil to $\mathrm{BD}$, the reaction rate constants of the reverse reaction for the first two reactions were larger than the reaction rate constants of the forward direction. In the same vein, Darnoko and Cheryan studied the kinetics of transesterification of palm oil into $\mathrm{BD}$ in the presence of $\mathrm{KOH}$ and methanol in a batch reactor and concluded that the kinetics is enhanced at higher temperatures up to a maximum conversion at $60^{\circ} \mathrm{C}$. Also the authors claimed that higher temperature operation has no influence on the time to reach maximum conversion [11]. Thus, kinetic study of transesterification reaction could predict the extent of the reaction at any time under particular conditions and also provide thermodynamic properties of the reaction [11]. However, few kinetic studies of transesterification of non edible oils into BD have been reported in open literature [7]. In addition, in spite of substantial reports on experimental studies of transesterification of Jatropha curcas (JC) oil to BD, as far as we know there is no open literature on the kinetic studies of JC oil into BD.

Recently, we reported biodesiel production from Nigerian JC oil and concluded that Nigerian JC oil is a potential feedstock for biodiesel production [6]. However in this study, kinetics of transesterification of JC oil into Biodiesel was not elucidated. Therefore as a follow up on this study, we hereby present kinetic study of homogeneously catalyzed transesterification of Nigerian JC oil into biodiesel. Understanding of the kinetic study and availability of dependable data on the kinetic study could pave the way for further optimization studies and also the development of heterogeneous catalysts for transesterification of JC oil to biodiesel. Advantages of heterogeneous catalysis over the homogeneous catalysis include reduction in operating costs for separation and purifica- tion process because the solid catalysts can easily be separated from products and re-used.

\section{Experimental}

\subsection{Material and Methods}

Jatropha curcas seeds were obtained from Ikere-Ekiti, a town in Nigeria. All the chemicals used in this study, such as, methanol, sodium hydroxide, anhydrous calcium chloride, concentrated sulphuric acid, 1-Oleoyl rac-glycerol, 1,2-dioleyol-rac-glycerol, methyl oleate, acetone, acetonitrile, n-hexane, were all of analytical grade purchased from Sigma Aldrich, Germany.

\subsection{Acid Esterification of Jatropha curcas Oil}

The oil from the seed was extracted according to the method of Akintayo [12]. The acid value of the crude JC oil was $35.8 \mathrm{mg} \mathrm{KOH/g} \mathrm{(17.9} \mathrm{FFA).} \mathrm{However,} \mathrm{previous}$ studies have shown that the free fatty acid (FFA) value in the oil should not be more than $1 \%$ [13], therefore, pre-treatment of the oil is necessary to reduce the acid content. Having measured the FFA of the oil, $2.25 \mathrm{~g}$ methanol and $0.05 \mathrm{~g}$ sulphuric acid for each gram of free fatty acid in the oil were added together and allowed to warm for about 15 minutes on a hot plate. This mixture was added slowly to the oil and agitated for one hour at $60^{\circ} \mathrm{C}-65^{\circ} \mathrm{C}$. After this, the mixture was allowed to settle and methanol-water mixture rose to the top. The methanol, water, and sulphuric acid layer were decanted. The bottom fraction is now the pre-treated oil and the FFA level was measured again to ensure it was less than $0.5 \%$. This method is according to the method of Berchmans and Hirata [14].

\subsection{Transesterification Reaction}

Transesterification reaction was carried out in batch process. The batch reactor consists of a $250 \mathrm{ml}$ Erlenmeyer flask containing $100 \mathrm{~g}$ of JC oil, alcohol and sodium hydroxide catalyst. The alcohol used was methanol and catalyst was $1 \% \mathrm{w} / \mathrm{w}$ of sodium hydroxide dissolved into an amount of alcohol according to the oil to alcohol ratio $1: 3,1: 4$, and 1:6. Firstly, the oil was heated up to a reaction temperature in the Erlenmeyer flask and the alcohol/catalyst mixture was added to the oil. These were done on a shaker at different reaction temperatures of $30^{\circ} \mathrm{C}, 45^{\circ} \mathrm{C}$ and $60^{\circ} \mathrm{C}$ keeping the rate of agitation constant at $200 \mathrm{rpm}$. The reaction was allowed to run for various reaction time 15 minutes, 30 minutes, 60 minutes, 120 minutes and 180 minutes to study the kinetics.

The sample collected was allowed to settle for twelve hours in a separating funnel by gravity settling into a clear, golden liquid biodiesel on the top with the light brown glycerol at the bottom. After this period, the glyc- 
erol was drained off from the bottom of the separating funnel. The raw biodiesel was water washed three times so as to remove the catalyst and glycerol. To ensure high purity biodiesel, a rotary evaporator was employed to remove excess methanol from the biodiesel. The high purity biodiesel was dried over anhydrous calcium chloride after which the analysis of the biodiesel was carried out.

\subsection{Analysis of Biodiesel Product}

Biodiesel produced was analyzed on an HPLC (LC20AB Prominence) equipped with $4.6 \mathrm{~mm} \mathrm{ID} \times 15 \mathrm{~cm}$ CLC-ODS (T) column (of $5 \mu \mathrm{m}$ particles and $100 \AA$ pore size) and consisted of a binary pump, a controller, an ultraviolet detector and an auto-sampler as auxiliary units. The HPLC also has two mobile phases: A cetonitrile and Acetone at 51:49 and at a flow rate of $0.7 \mathrm{~mL} \cdot \mathrm{min}^{-1}$. Acetone was used to make $1 \mathrm{mg} / \mathrm{ml}$ of the sample. $10 \mu \mathrm{l}$ of the sample was injected into an auto-sampler vials. The HPLC analysis was conducted according to the method proposed by Dubé et al. and Darnoko and Cheryan [11,15].

\section{Results and Discussion}

The kinetic study for the transesterification of the oil was carried out for the alkali catalyzed reaction.

\subsection{Kinetic Study of the Transesterification of JC Oil}

Alkali catalyzed transesterification of the pre-treated $\mathrm{Ja}$ tropha curcas oil were studied at three temperatures $\left(30^{\circ} \mathrm{C}, 45^{\circ} \mathrm{C}\right.$ and $\left.60^{\circ} \mathrm{C}\right)$ and oil to alcohol molar ratios $(1: 3,1: 4$ and $1: 6)$. The transesterification reaction is a stepwise reaction consisting of a number of consecutive irreversible reactions as shown in Equations 1 to 3 above. Typical concentration profiles of triglycerides (TG), diglycerides (DG), monoglycerides (MG), methyl esters (ME) and glycerol (GL) for the alkali transesterification of both oils with oil to methanol ratio of 1:6 using 1\% w/w $\mathrm{NaOH}$ are depicted in Figures 1-3. These Figures clearly show that concentrations of the triglycerides, diglycerides and monoglycerides decrease with time while concentrations of glycerol and methyl esters increase with time. This is in line with the work of Freedman et al. [9].

\subsection{Determination of Rate Determining Step (RDS) of Alkali Catalysed Transesterification of JC Oil}

The effective reaction rate constants $\left(k_{1}, k_{2}, k_{3}\right)$ were defined for forward reactions and calculated based on the experimental data obtained for the period of the reaction. The equations used to calculate the effective reaction rate constants of the reactions were based on first order equation. This is because the alcohol used; methanol was

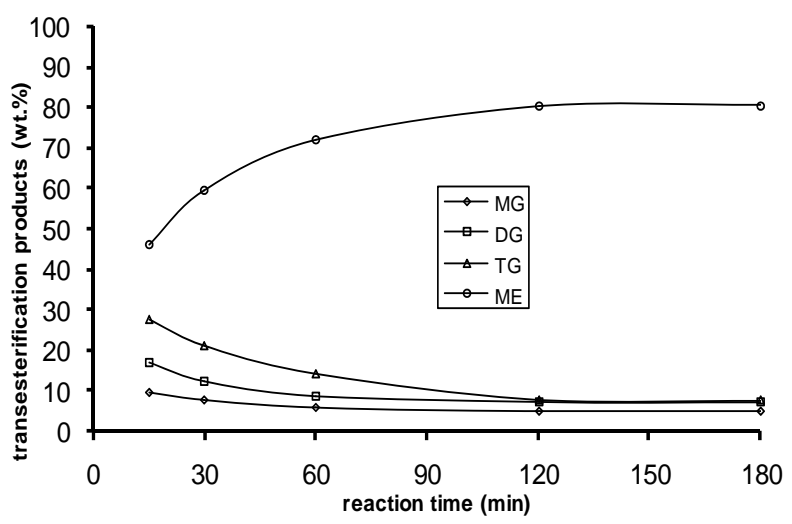

(a)

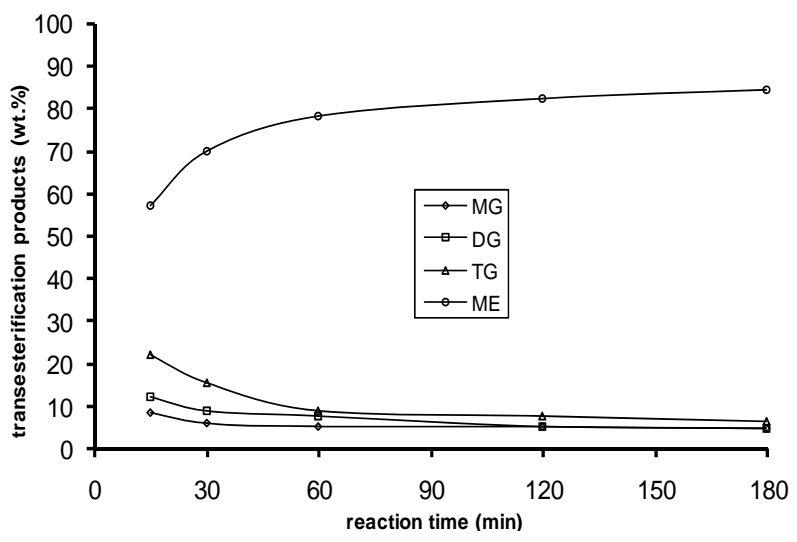

(b)

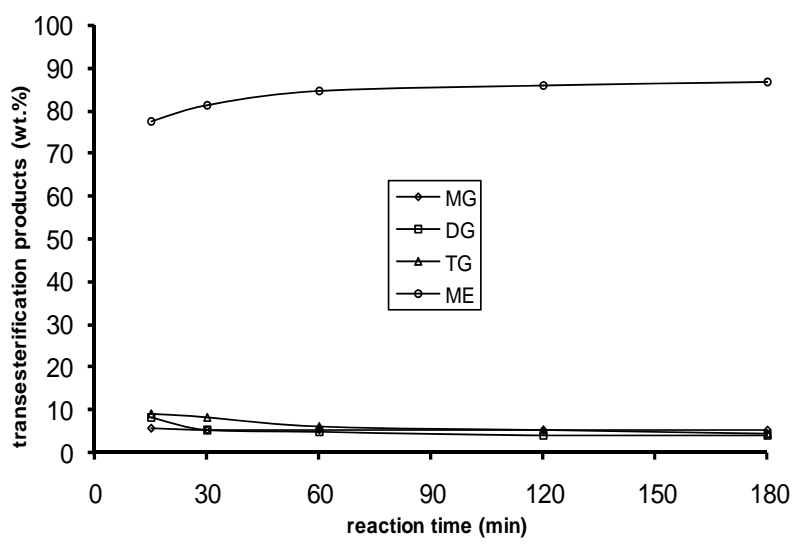

(c)

Figure 1. Transesterification product of Jatropha curcas oil at $60^{\circ} \mathrm{C}$ as a function of Oil to Methanol molar ratio: (a) 1:3; (b) $1: 4$; (c) $1: 6$.

in excess over what is required stiochiometrically while the triglyceride was the limiting reagent. Assuming a first order reaction for the overall reaction involved in the transesterification of $\mathrm{TG}$ to $\mathrm{BD}$ and $\mathrm{GL}$, the overall rate equation is:

$$
[T G]=[T G]_{o} \exp (-k t)
$$

Linearizing Equation (7) gives: 


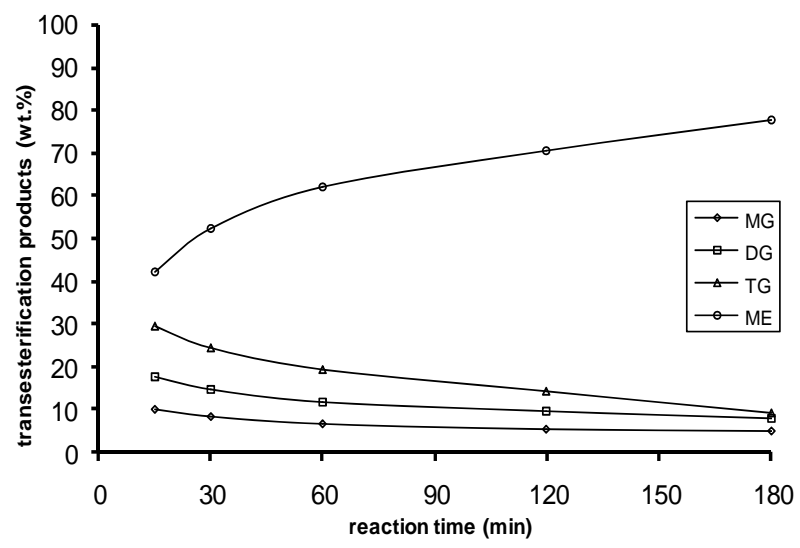

(a)

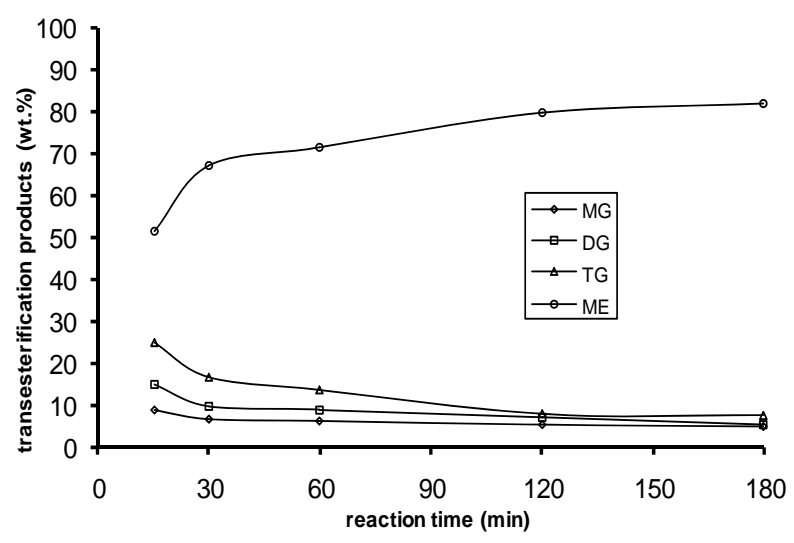

(b)

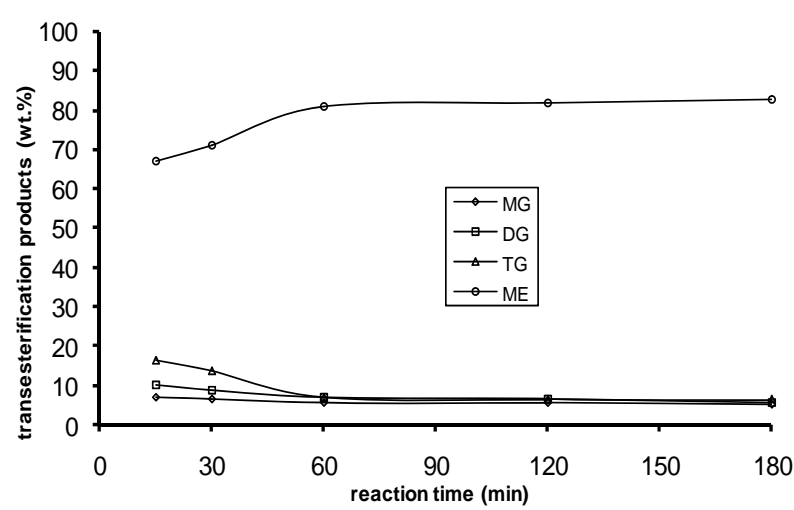

(c)

Figure 2. Transesterification product of Jatropha curcas oil at $45^{\circ} \mathrm{C}$ as a function of Oil to Methanol molar ratio: (a) 1:3; (b) 1:4; (c) 1:6.

$$
\ln [T G]=\ln [T G]_{O}-k t
$$

where $[T G]$, is the concentration of $T G$ at time, $t$; $[T G]_{0}$, the concentration at initial stage of the reaction $(t=0)$ and $k$, is the reaction rate constant (1/s). A plot of $\ln [T G]$ against $t$, is expectedly a linear relationship with $k$ deduced from the slope of the plot. As a validation of our assumption of first order for TG to BD, the plot of $\ln [T G]$ versus $t$ during the first 60 minutes of

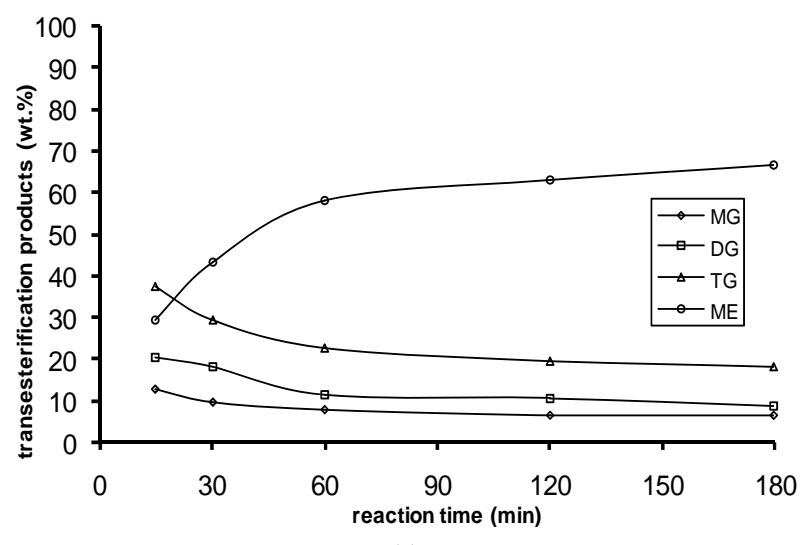

(a)

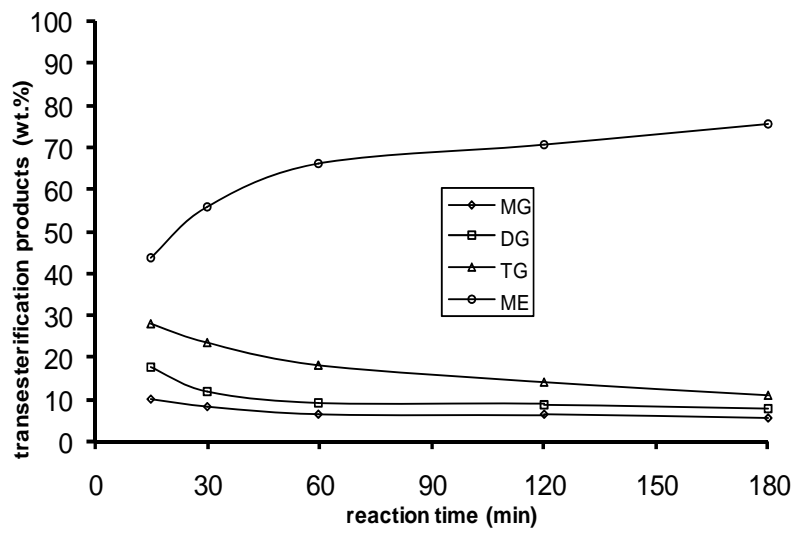

(b)

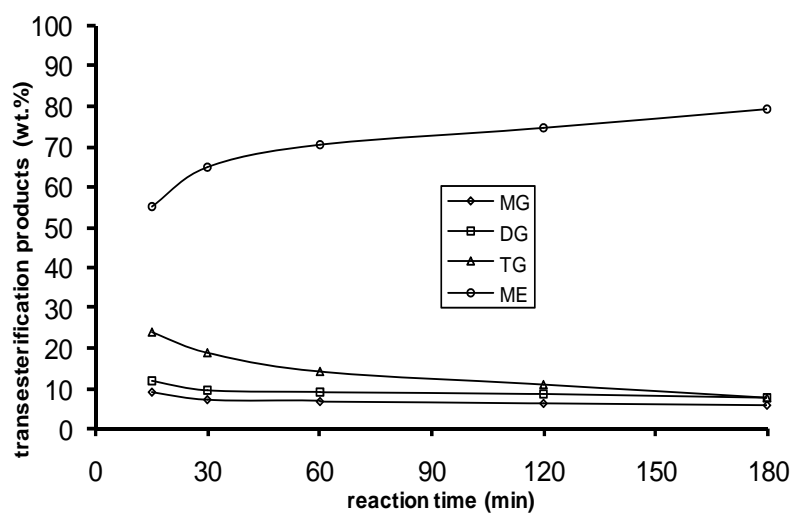

(c)

Figure 3. Transesterification product of Jatropha curcas oil at $30^{\circ} \mathrm{C}$ as a function of Oil to Methanol molar ratio: (a) 1:3; (b) 1:4; (c) 1:6.

the reaction, depicted in Figure 4, shows a linear relation, indicating that the transesterification of $\mathrm{TG}$ to $\mathrm{BD}$ in the presence of excess methanol can be speculated to be first order reaction. This is consistent with the study of Freedman et al. [9] in which the estimation of the effective rate constants in their work was based on first order equation.

The effective reaction rate constants calculated for transesterification of the oil are shown in Table 1. The 


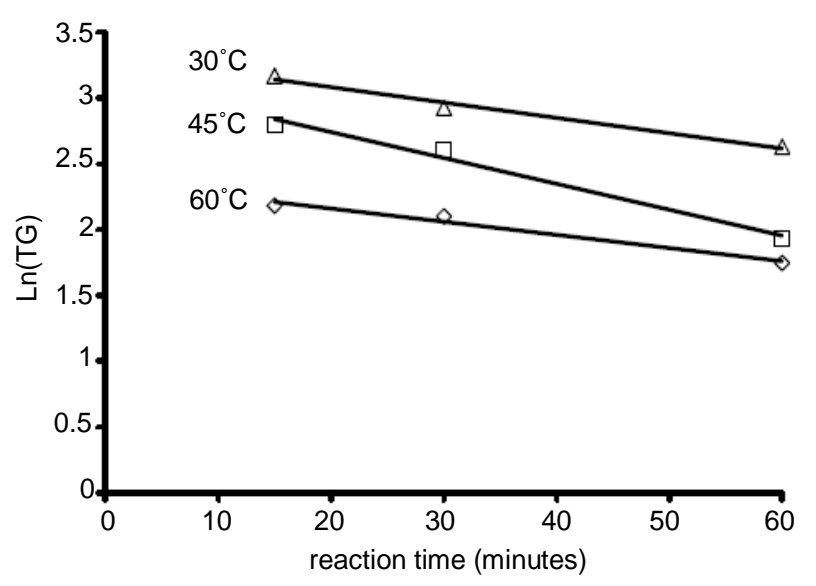

Figure 4. The plot of $\ln [\mathrm{TG}]$ against reaction time (t) during the first 60 minutes of the reaction at reaction temperatures $30^{\circ} \mathrm{C}, 45^{\circ} \mathrm{C}$ and $60^{\circ} \mathrm{C}$.

Table 1. The rate constants of transesterification of refined Jatropha curcas oil at different oil to alcohol molar ratios and at different temperatures.

\begin{tabular}{|c|c|c|c|c|c|}
\hline $\begin{array}{c}\text { Step } \\
\text { Reaction }\end{array}$ & $\begin{array}{c}\text { Reaction Rate } \\
\text { Constant }\end{array}$ & $\begin{array}{c}\text { Oil/Alcohol } \\
\text { Ratio }\end{array}$ & $30^{\circ} \mathrm{C}$ & $45^{\circ} \mathrm{C}$ & $60^{\circ} \mathrm{C}$ \\
\hline \multirow{3}{*}{ TG-DG } & \multirow{3}{*}{$\mathrm{K}_{1}$} & $1: 3$ & 0.195 & 0.273 & 0.385 \\
\hline & & $1: 4$ & 0.165 & 0.257 & 0.338 \\
\hline & & $1: 6$ & 0.111 & 0.163 & 0.389 \\
\hline \multirow{3}{*}{ DG-TG } & \multirow{3}{*}{$\mathrm{K}_{11}$} & $1: 3$ & 4.183 & 5.168 & 6.386 \\
\hline & & $1: 4$ & 3.143 & 3.688 & 4.625 \\
\hline & & $1: 6$ & 1.584 & 1.723 & 2.156 \\
\hline \multirow{3}{*}{ DG-MG } & \multirow{3}{*}{$\mathrm{K}_{2}$} & $1: 3$ & 0.199 & 0.288 & 0.380 \\
\hline & & $1: 4$ & 0.211 & 0.320 & 0.405 \\
\hline & & $1: 6$ & 0.183 & 0.243 & 0.457 \\
\hline \multirow{3}{*}{ MG-DG } & \multirow{3}{*}{$\mathrm{K}_{22}$} & $1: 3$ & 3.539 & 4.625 & 5.618 \\
\hline & & $1: 4$ & 2.475 & 3.094 & 4.000 \\
\hline & & $1: 6$ & 2.203 & 2.574 & 2.822 \\
\hline \multirow{3}{*}{ MG-GL } & \multirow{3}{*}{$\mathrm{K}_{3}$} & $1: 3$ & 0.752 & 1.204 & 1.612 \\
\hline & & $1: 4$ & 1.018 & 1.212 & 1.489 \\
\hline & & $1: 6$ & 0.650 & 1.003 & 1.380 \\
\hline \multirow{3}{*}{ GL-MG } & \multirow{3}{*}{$\mathrm{K}_{33}$} & $1: 3$ & 3.700 & 4.901 & 5.400 \\
\hline & & $1: 4$ & 3.168 & 3.812 & 4.623 \\
\hline & & $1: 6$ & 2.558 & 3.450 & 4.400 \\
\hline
\end{tabular}

effective reaction rate constant for the triglyceride conversion is the lowest of all the effective reaction rate constants for forward reactions at all reaction temperatures (See Table 1). This indicates that the rate determining step (RDS) for overall alkali catalyzed trans- esterification of Jatropha curcas oil is the conversion of triglyceride to diglyceride. For instance at oil/alcohol molar ratio of $1: 6$, the magnitude of the reaction rate constants is in the descending order: $k_{G L-M G}>k_{M G-D G}$ $>k_{D G-T G}>k_{M G-G L}>k_{D G-M G}>k_{T G-D G}$. The reaction rate constants increased from $0.389-1.380 \mathrm{~h}^{-1}$ at $60^{\circ} \mathrm{C}$ for a oil/alcohol molar ratio of $1: 6$. Also, the reaction rate constants increased with temperature for the entire molar ratio. This indicates that the rate determining step (RDS) of transesterification of the oil is favoured at higher temperatures. This is a typical observation for an endothermic reaction.

\subsection{The Activation Energy}

The activation energy determines the extent of dependency of rate constants on reaction temperature at a given condition. The activation energies of the RDS (Conversion of triglyceride to diglyceride) at different oil to alcohol ratio were calculated based on the Arrhenius equation (Equation (5)). Some of the Arrhenius plots for RDS are presented in Figure 5 for the transesterification of both oils at three different temperatures $\left(30^{\circ} \mathrm{C}, 45^{\circ} \mathrm{C}\right.$, and $60^{\circ} \mathrm{C}$ ). The correlation coefficients for Arrhenius plot of the RDS of transesterification of the oils in all these cases exceed 0.92. Table 2 shows activation energy and the corresponding correlation coefficients of the RDS and its backward reaction of transesterification of refined soybean oil and Jatropha curcas oil. Activation energies in this study ranged from $19.122-34.921 \mathrm{~kJ} / \mathrm{mol}$ (See Table 2) for conversion of triglyceride to diglyceride. These values are within the range reported in the literature. For instance, Vicente et al. [16] studied the methanolysis of sunflower oil, and reported activation energy of $31.7 \mathrm{~kJ} / \mathrm{mol}$ from triglyceride to diglyceride. Activation energy shows how strong the rate of reaction depends on reaction temperature. Activation energy of the backward reaction is somewhat lower than that of the forward one, indicating that the product diglyceride is less stable and has higher potential energy than the reactant, triglyceride. In this type of reaction, heat is absorbed from the surroundings to the reactant mixture. Therefore, it can be concluded that the RDS of the oils' methanolysis using $\mathrm{NaOH}$ as a catalyst was an endothermic reaction.

\section{Conclusions}

The highest yield obtained from the pre-treated Jatrophacurcas oil was $86.61 \% \mathrm{w} / \mathrm{w}$ for alkali catalysis method of transesterification. In this study, the rate of formation of ester can be increased by increasing reaction temperature and oil to alcohol molar ratio, therefore the best condition to carry out biodiesel production is at $60^{\circ} \mathrm{C}$ with oil to alcohol ratio of 1:6. 


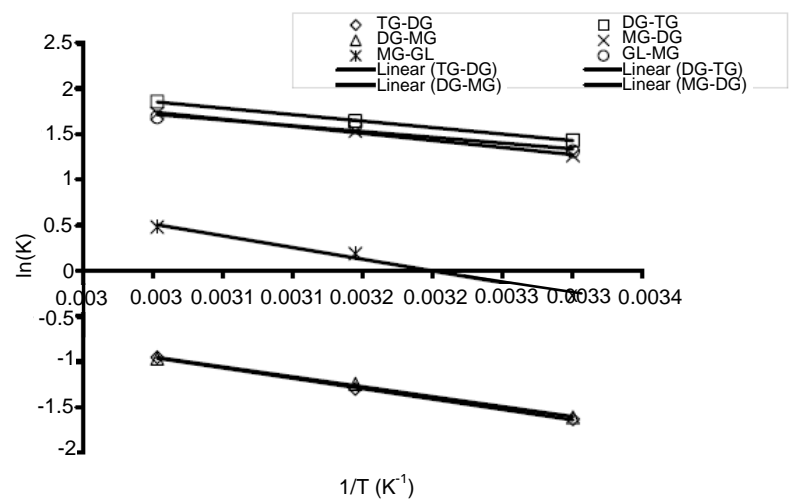

(a)

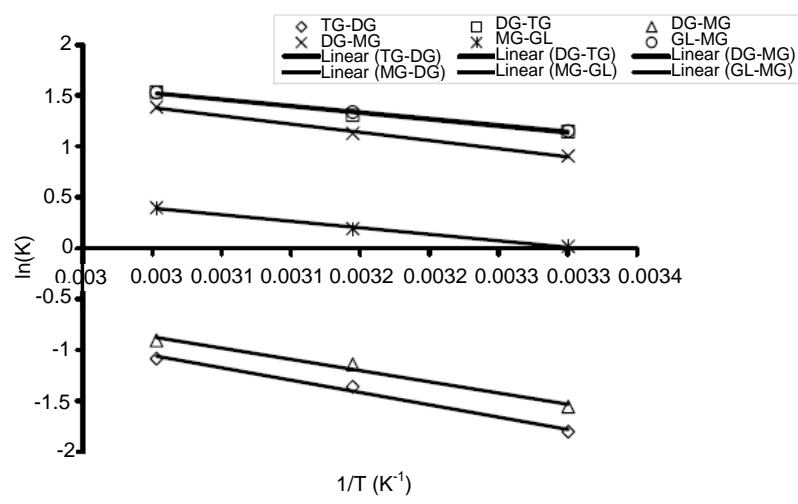

(b)

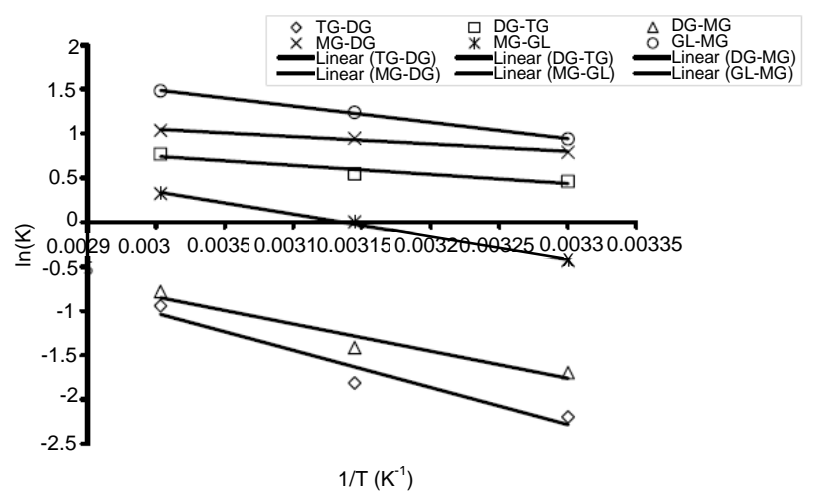

(c)

Figure 5. Arrhenius plots for rate determining step of transesterification of refined Jatropha curcas oil for varied oil to alcohol molar ratio (A) at 1:3 (B) at 1:4 (C) at 1:6.

The concentrations of the triglycerides, diglycerides and monoglycerides decrease with time while methyl esters increase with time for both methods of catalysis but glycerol increases with time in alkali catalysis method. Activation energies in this study ranged from $19.12 \mathrm{~kJ} \cdot \mathrm{mol}^{-1}$ to $34.92 \mathrm{~kJ} \cdot \mathrm{mol}^{-1}$ for refined Jatropha curcas oil for conversion of triglyceride to diglyceride. Conversion of triglyceride to diglyceride was found to be the rate determining step (RDS) of the overall reaction because activation energy of the backward reaction is
Table 2. Activation energies for alkali catalyzed transesterification of refined JC oil at different conditions.

\begin{tabular}{|c|c|c|c|}
\hline Reaction & $\begin{array}{c}\text { Oil/Alcohol } \\
\text { Ratio }\end{array}$ & $\begin{array}{c}\text { Activation } \\
\text { Energy }(\mathrm{KJ} / \mathrm{Mol})\end{array}$ & $\begin{array}{l}\text { Correlation } \\
\text { Coefficient }\end{array}$ \\
\hline \multirow{3}{*}{ TG-DG } & $1: 3$ & 19.122 & 0.9996 \\
\hline & $1: 4$ & 19.955 & 0.9880 \\
\hline & $1: 6$ & 34.921 & 0.9410 \\
\hline \multirow{3}{*}{ DG-TG } & $1: 3$ & 11.832 & 0.9993 \\
\hline & $1: 4$ & 10.809 & 0.9848 \\
\hline & $1: 6$ & 8.315 & 0.9198 \\
\hline \multirow{3}{*}{ DG-MG } & $1: 3$ & 18.109 & 0.9968 \\
\hline & $1: 4$ & 18.259 & 0.9996 \\
\hline & $1: 6$ & 25.534 & 0.9850 \\
\hline \multirow{3}{*}{ MG-DG } & $1: 3$ & 12.954 & 0.9958 \\
\hline & $1: 4$ & 13.411 & 0.9956 \\
\hline & $1: 6$ & 12.447 & 0.9604 \\
\hline \multirow{3}{*}{ MG-GL } & $1: 3$ & 21.385 & 0.9879 \\
\hline & $1: 4$ & 10.809 & 0.9946 \\
\hline & $1: 6$ & 21.086 & 0.9962 \\
\hline \multirow{3}{*}{ GL-MG } & $1: 3$ & 10.643 & 0.9394 \\
\hline & $1: 4$ & 10.572 & 0.9986 \\
\hline & $1: 6$ & 15.207 & 0.9989 \\
\hline
\end{tabular}

somewhat lower than that of the forward one. This indicates that the product diglyceride is less stable and has higher potential energy than the reactant triglyceride. In this type of reaction, heat is absorbed from the surroundings in the reactant mixture. Therefore, it could be concluded that the RDS of the oils' methanolysis using $\mathrm{NaOH}$ as a catalyst was an endothermic reaction

\section{REFERENCES}

[1] F. Chai, F. Cao, F. Zhai, Y. Chen, X. Wang and Z. Su, "Transesterification of Vegetable Oil to Biodiesel Using a Heteropolyacid Solid Catalyst," Advanced Synthesis \& Catalysis, Vol. 349, No. 7, 2007, pp. 1057-1065. doi:10.1002/adsc.200600419

[2] A. Dhar, R. Kevin and A. K. Agarwal, "Production of Biodiesel from High-Ffa Neem Oil and Its Performance, Emission and Combustion Characterization in a Single Cylinder Dici Engine," Fuel Processing Technology, Vol. 97, 2012, pp. 118-129. doi:10.1016/j.fuproc.2012.01.012

[3] J. H. Ng, H. K. Ng and S. Gan, "Advances in Biodiesel Fuel for Application in Compression Ignition Engines," Clean Technologies and Environmental Policy, Vol. 12, No. 5, 2010, pp. 459-493. 


\section{doi:10.1007/s10098-009-0268-6}

[4] E. Aransiola, E. Betiku, D. Ikhuomoregbe and T. Ojumu, "Production of Biodiesel from Crude Neem Oil Feedstock and Its Emissions from Internal Combustion Engines," African Journal of Biotechnology, Vol. 11, No. 22, 2012. doi:10.5897/AJB11.2301

[5] E. Aransiola, T. Ojumu, O. Oyekola and D. Ikhuomoregbe, "A Study of Biodiesel Production from Non-Edible Oil Seeds: A Comparative Study," The Open Conference Proceedings Journal, Vol. 3, Suppl. 2-M1, 2012, pp. 18-22.

[6] E. F. Aransiola, M. O. Daramola, T. V. Ojumu, M. O. Aremu, S. K. Layokun and B. O. Solomon, "Nigerian Jatropha Curcas Oil Seeds: Prospect for Biodiesel Production in Nigeria," International Journal of Renewable Energy Research (IJRER), Vol. 2, No. 2, 2012, pp. 317-325.

[7] S. Jain and M. Sharma, "Kinetics of Acid Base Catalyzed Transesterification of Jatropha curcas Oil," Bioresource Technology, Vol. 101, No. 20, 2010, pp. 7701-7706. doi:10.1016/j.biortech.2010.05.034

[8] J. C. Juan, D. A. Kartika, T. Y. Wu and T. Y. Y. Hin, "Biodiesel Production from Jatropha Oil by Catalytic and Non-Catalytic Approaches: An Overview," Bioresource Technology, Vol. 102, No. 2, 2011, pp. 452-460. doi:10.1016/i.biortech.2010.09.093

[9] B. Freedman, R. O. Butterfield and E. H. Pryde, "Transesterification Kinetics of Soybean Oil 1," Journal of the American Oil Chemists' Society, Vol. 63, No. 10, 1986, pp. 1375-1380.
[10] H. Noureddini and D. Zhu, "Kinetics of Transesterification of Soybean Oil," Journal of the American Oil Chemists' Society, Vol. 74, No. 11, 1997, pp. 1457-1463.

[11] D. Darnoko and M. Cheryan, "Kinetics of Palm Oil Transesterification in a Batch Reactor," Journal of the American Oil Chemists' Society, Vol. 77, No. 12, 2000, pp. 1263-1267.

[12] E. Akintayo, "Characteristics and Composition of Parkia Biglobbossa and Jatropha curcas Oils and Cakes," Bioresource Technology, Vol. 92, No. 3. 2004, pp. 307-310. doi:10.1016/S0960-8524(03)00197-4

[13] M. Mittelbach, "Diesel Fuel Derived from Vegetable Oils, Vi: Specifications and Quality Control of Biodiesel," Bioresource Technology, Vol. 56, No. 1, 1996, pp. 7-11. doi:10.1016/0960-8524(95)00172-7

[14] H. J. Berchmans and S. Hirata, "Biodiesel Production from Crude Jatropha curcas L. Seed Oil with a High Content of Free Fatty Acids," Bioresource Technology, Vol. 99, No. 6, 2008, pp. 1716-1721. doi:10.1016/j.biortech.2007.03.051

[15] M. A. Dubé, S. Zheng, D. D. McLean and M. Kates, "A Comparison of Attenuated Total Reflectance-Ftir Spectroscopy and Gpc for Monitoring Biodiesel Production," Journal of the American Oil Chemists' Society, Vol. 81, No. 6, 2004, pp. 599-603.

[16] G. Vicente, M. Martínez, J. Aracil and A. Esteban, "Kinetics of Sunflower Oil Methanolysis," Industrial \& Engineering Chemistry Research, Vol. 44, No. 15, 2005, pp. 5447-5454. doi:10.1021/ie040208j 